\title{
The Application of PEST Analysis and POCD Framework to Skydio's Venture Capital Investment
}

\author{
Ziyi Jiang ${ }^{1, \dagger}$, Jiyao Sun ${ }^{2, \dagger}$ Ke Wei ${ }^{3, *, \dagger}$ \\ ${ }^{1}$ Kogod Busines School,American University, Washighton DC, 20016, United States \\ ${ }^{2}$ Business College, Liaoning University, Shenyang, 110136, China \\ ${ }^{3}$ Business School, University of International Business and Economics, Beijing, 100029, China \\ ${ }^{*}$ Corresponding author. Email: 201806098@uibe.edu.cn \\ ${ }^{\dagger}$ These authors contribute equally.
}

\begin{abstract}
Successful venture capital assessment needs accurate and efficient analysis models. This paper conducts a comprehensive analysis on Skydio to evaluate the investment value of this enterprise in order to invest in venture capital. We first survey the company's overall situation, including the enterprise property, history, and investment status. Secondly, based on PEST analysis that consists of an enterprises' political environment, economic environment, social environment, and technological environment, we analyze the main external environment factors and the company`s opportunities and risks. Then, the POCD framework is applied to analyze Skydio's operating environment and investment evaluation through the perspective of People, Opportunity, and Context. Finally, through all the analysis, Skydio is undoubtedly the leader of unicorn enterprises and has great investment value. We are optimistic about Skydio and believe the company is worth investing in. This paper provides a better forecasting method to apply PEST analysis and POCD framework to analyzing start-up companies for venture capital.
\end{abstract}

Keywords: Venture capital, PEST analysis, POCD framework.

\section{INTRODUCTION}

Venture Capital Investment involves investing with venture capital. According to the definition of the National Venture Capital Association of the United States, it is equity capital invested by professional financiers into emerging, rapidly developing enterprises with great competitive potential. Venture capital can also be understood as a dynamic cycle process. Risk investors who have their own relevant industry or professional trade knowledge and practical experience, combined with efficient management skills and financial expertise, actively participate in enterprise or risk project management, until the risk projects go publicly listed or go through mergers and acquisitions that achieve capital appreciation and capital mobility. After the withdrawal of a round of venture capital investment, the capital will be invested in the next selected venture enterprises or venture projects, so that the cycle continues to obtain venture capital appreciation. For VC, it is necessary to try to find projects with a high probability of success, such as projects with a large future market, high product value, high competition barrier, less competition or big competitive advantage at the present stage, and reliable management team. Because the project is relatively early and far from a success, it is more of a qualitative analysis, which requires a good grasp of logic. Moreover, VC needs to find as many eggs as possible to invest to disperse risks. Therefore, VC needs strong connections among investors.

This paper mainly introduces Skydio's business, enterprise value, founder and industry position, and analyzes the core competitiveness of the company and whether there is investment value through PeopleOpportunity-Context-Deal (POCD) analysis.

Using Political-Economic-Social-Technological (PEST) analysis framework to analyze the company is an appealing choice because it can show the main external environmental factors that a company faces. Carruthers [1] discussed some of the factors that might add to the PEST model when applying the model to veterinary practice. And he found that it was very useful to assess the business environment and improve business performance. Gupta [2] thought when applying environment and pest analysis to external business 
environment, it was necessary to consider the industry life because it varied according to the stage of the industry evolution. Ha \& Coghill [3] succeeded in using the PEST model to analyze the E-government in Singapore. Jaroslav [4] discussed the possible applications of PEST analysis and argued that the combination of PEST and reports by European Bank for Reconstruction and Development and International Bank for Reconstruction and Development is seen as a viable tool for measuring the market potential, its growth or decline. Jae \& Geun [5] used PEST combined with 4Ps analysis to reveal the secret behind building a global brand when applying to the Microsoft Company.

POCD or PCDO framework has recently attracted large numbers of profound studies due to their convenience and high accuracy when applying to startups. And this, in turn, contributes to their rapid development. Sahlman [6] firstly argued that the PCDO framework could be used to analyze the structure and governance of venture-capital organizations. Barnardo, Reyneke, Ferreira and Robertson [7] though it was very useful to use the POCD framework to evaluate the best strategic actions to grow a business through the lens of sustainable entrepreneurship. Johnson \& Ebben [8] argued that people especially students could apply this model to formally explore opportunity identification. Lukeš [9] thought it was a good criterion for selecting a good entrepreneurial team. Aure [10] thought the PCDO framework could be used to build a framework about the management of a social enterprise's commercial and social value propositions.

For the research methods, we mainly analyze its internal and external conditions. We conducted in-depth analysis through two models, including the PEST analysis by Johnson $\mathrm{G}$ and Scholes $\mathrm{K}$, which is for the macroeconomic environment of enterprise and investment evaluation, and fully analyzed the political environment and policies, social environment, and technological environment. In addition, the POCD framework is used for analyzing the structure and governance of venture capital the operating environment of an enterprise which mainly conducts a comprehensive investment evaluation by analyzing the man-enterprise operating personnel, enterprise opportunities, and the environment faced by the enterprise. Finally, after thorough and accurate research, we can conclude that Skydio is a thriving, high-quality business worth investing in.

For the overall arrangement, we first introduced the overall situation of the company in section 2 . Then, section 3 uses the PEST model to analyze the opportunities and risks that the company faces. For section 4 focuses on the POCD framework to analyze the value of Skydio. The last section presents our conclusions.

\section{FIRM DESCRIPTION}

Skydio, founded in 2014, is an American start-up company headquartered in Redwood City, California. Its main business is the production of fully autonomous flying drones that can lock on to their subjects and avoid obstacles while filming. The drones are controlled by breakthrough AI and satisfy the use by consumers, enterprises, and government customers. The ultimate goal is to make flying a drone as easy as opening an App. If drones become easy to operate, they could become a platform that everyone is trying to access.

Table 1 shows the history of financing conditions. Andreessen Horowitz led Skydio's Series A funding round. Skydio closed a $\$ 170$ million Series D funding round led by Andreessen Horowitz's Growth Fund, Linse Capital, Next47, IVP and UP. Partners. This brings total funding raised to over $\$ 340$ million with a current valuation of over $\$ 1$ billion.

Table 1. The history of financing

\begin{tabular}{|c|c|c|}
\hline Round & Amount & Styles Investors \\
\hline Seed & \$3 million & $\begin{array}{l}\text { Accel Partners, Andreessen Horowitz, } \\
\text { Buddy Arnheim }\end{array}$ \\
\hline Series A & \$25 million & $\begin{array}{l}\text { Accel Partners, Andreessen Horowitz, } \\
\text { CAA Ventures }\end{array}$ \\
\hline Series B & $\$ 42$ million & $\begin{array}{l}\text { Accel Partners, Andreessen Horowitz, } \\
\text { Nvidia, Playground Global, IVP } \\
\text { (Institutional Venture Partners), Kevin } \\
\text { Durant, Parcel B }\end{array}$ \\
\hline Series C & $\$ 100$ million & $\begin{array}{l}\text { Andreessen Horowitz, NTT DOCOMO } \\
\text { Ventures, IVP, Playground Global, } \\
\text { next47, A16z }\end{array}$ \\
\hline Series D & $\$ 170$ million & $\begin{array}{l}\text { Andreessen Horowitz`s Growth Fund, } \\
\text { Linse Capital, Next47, IVP and } \\
\text { UP.Partners }\end{array}$ \\
\hline
\end{tabular}




\section{PEST ANALYSIS}

PEST analysis (Political, Economic, Social, and Technical) is a management method whereby an organization assesses the major external factors affecting its operations to be more competitive in the marketplace. As the acronym describes, these four domains are at the center of the model. In this part, PEST analysis is used to analyze this enterprise and evaluate its investment value.

\subsection{Political \& Legal Environment}

The United States' policy on UAV is still uncertain, and the external environment is still not clear. However, this issue will be changed to a great extent.

\subsubsection{Some restrictions on drones in the United States}

The political and legal environment is one of the most important aspects of the U.S. drone industry that can prohibit or allow these unmanned aerial vehicles (UAVs) or drones to fly around the United States. The US drone industry is now under the Federal Aviation Administration (FAA) control, part of the US Department of Transportation. The FAA has full authority to regulate and supervise all aspects of American aviation. Drones are now open for noncommercial use but are subject to certain rules. In addition, one commercial use, the commercial production of TV shows and movies, are currently only allowed to be used by six companies, while other commercial drones are still banned.

\subsubsection{Policy preference for the drone industry}

However, the FAA has discussed the possibility of drafting regulations for commercial drone flights by 2015 . Discussions will begin with restrictions on flights of drones weighing less than 55 pounds, which covers the majority of commercial drones on the market. Besides, UPS said in October 2019 that it had received the first full approval from the US government to operate UAV routes. Last year, wing, Google's sister company, became the first company to be certified as a U.S. air carrier operating a single pilot drone. In August 2020, the US federal government approved Amazon's UAV service to start testing the commercial distribution service of the
UAV fleet. American robotics is one of the first UAV companies specially authorized by the FAA. The authorized company can control UAV flight by BVLOS(out of the line of sight). The UAV in the future can be fully automatic, with no operator to follow. So it is obvious that the UAV industry will develop well in the future. And it is an opportunity for Skydio.

\subsection{Economic Environment}

For the study of the economic environment, we divided it into two parts for analysis. The first part is the impact of the minimum wage increase on the UAV industry, and the other part is the analysis of some key indicators such as annual income rate, employment rate and GDP.

\subsubsection{Increase in minimum wage become a driving force}

According to the U.S. Bureau of labor statistics, the national minimum wage in the United States continues to rise every year. It is very reasonable for many companies to replace labor with UAV technology. In the next 10 years, the trend of using UAVs seems to be gradually increasing. UAVs are usually used in national military departments and civil fields, including commercial UAVs. Since the last time, almost $100 \%$ of UAVs have been used only in the military sector. However, the proportion between national defense UAV and civil $\mathrm{UAV}$ is always changing. Bi intelligence claims that by the end of 2023, $12 \%$ of the UAVs on the market will be civilian UAVs. It will be the result of a law approved by the House of Lords on the use of commercial drones.

\subsubsection{Key indicators show the recovery}

\section{(1) Annual income rate}

To further analyze the economic environment, data from the Bureau of Economic Analysis are used in Figure 1. The nation's personal income rose $59.7 \%$ in the first quarter of 2021 , after falling $3.9 \%$ in the fourth quarter of 2020. In the first quarter of 2021, growth in transfer payments was the major contributor to growth in personal income in all states and the District of Columbia. Changes in personal income ranged from $89.3 \%$ in Mississippi to $31.1 \%$ in the District of Columbia. 


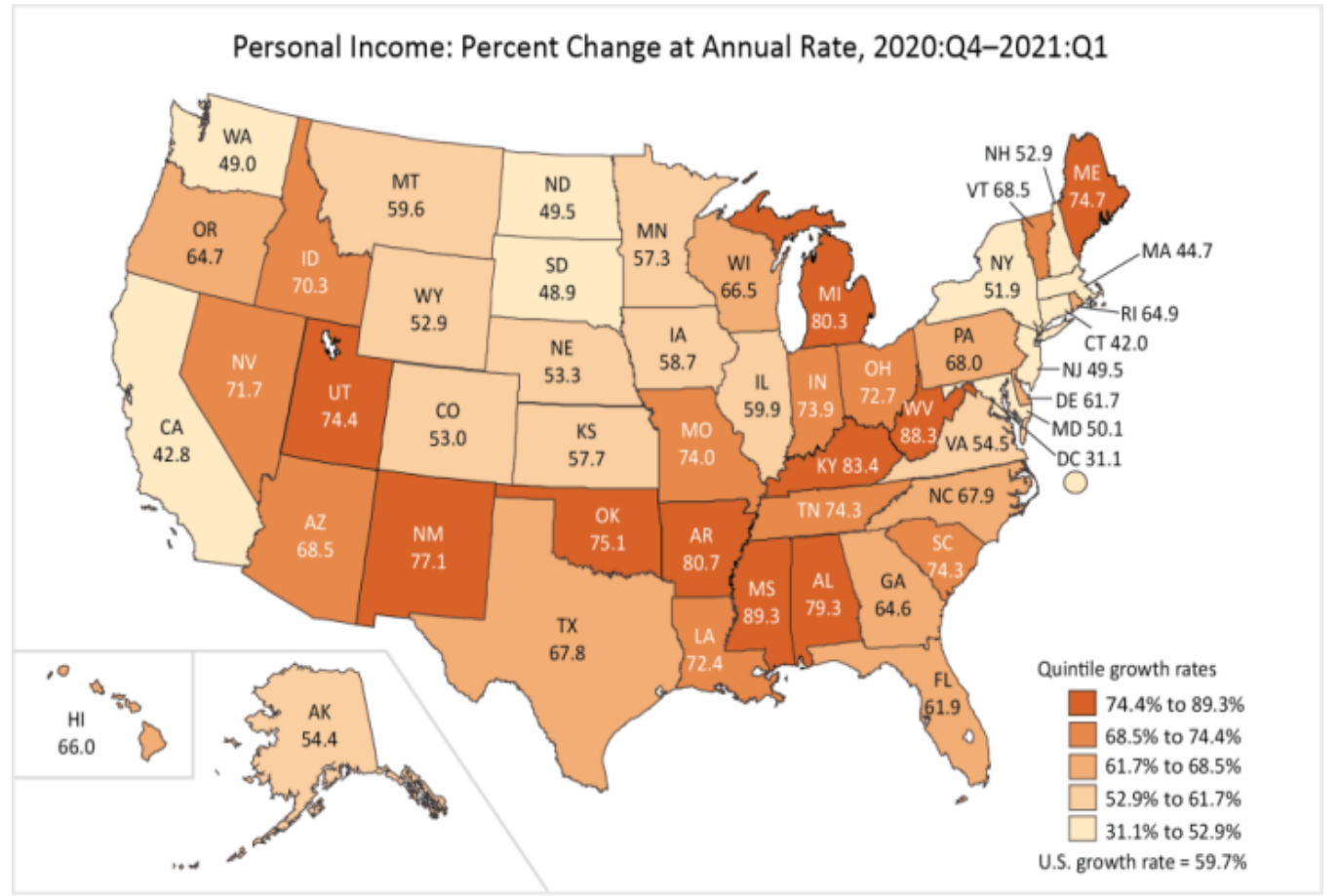

U.S. Bureau of Economic Analysis

Figure 1. Personal Income by State, 1st Quarter 2021

Source: Bureau of Economic Analysis

\section{(2) Unemployment rate}

Another important indicator is the unemployment rate, we search from Trading economic.com--U.S. Bureau of Labor Statistics and results are shown in Figure 2. The U.S. unemployment rate fell to $5.8 \%$ in May 2021, the lowest since March 2020 and below market expectations of $5.9 \%$. That is a further sign that the job market is consolidating its recovery as the economy further reopens. A steady decline in the number of coronavirus cases per day thanks to vaccination has allowed the authorities to lift restrictions on businesses. Still, employers have been complaining that they cannot find enough workers to cope with the growing demand. The number of unemployed people was 9.32 million, down by 496,000 . The number of employed people was 151.62 million, an increase of 444,000 .

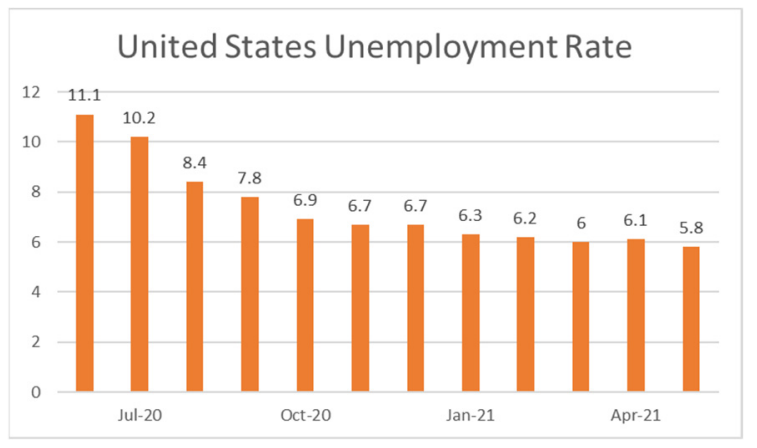

Figure 2. United States Unemployment Rate

\section{(3) Real GDP}

The last indicator surveyed is Real GDP, which we gather the results in Figure 3 from the U.S. Bureau of Economic Analysis (Seasonally adjusted at an annual rate). In the first quarter of 2021, the real gross domestic product grew at an annualized rate of $6.4 \%$, reflecting the continued economic recovery, the reopening of businesses, and the government's continued response to the COVID-19 pandemic. In the first quarter of this year, the government made direct economic impact payments, expanded unemployment benefits, and Wage Security Program loans to families and businesses through the COVID-19 Response and Relief Supplementary Appropriations Act and America's Relief Plan Act.

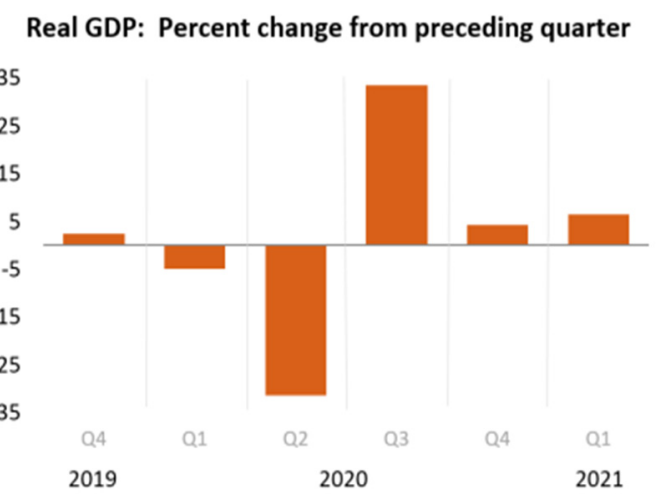

Figure 3. GDP by Industry, and Corporate Profits (Revised), 1st Quarter 2021

Source: U.S. Bureau of Economic Analysis (Seasonally adjusted at an annual rate) 


\subsection{Socio-Cultural Environment}

It seems that the UAV industry does not have so much social power, because most of the UAV adoption is a Business-to-Business industry. UAVs are mainly used for military or commercial purposes. However, the security of American citizens is one of the top priorities of American society. Commercial UAVs will definitely be used in public areas, which will increase the probability of accidents. Therefore, the public and the government still have a lot of criticism on this issue. Therefore, research and development in this field still leave a gap for enterprises to solve. On the other hand, ethical issues have been questioned, whether people's privacy will be interrupted. Besides on December 29, 2020, The U.S. Federal Aviation Administration (FAA) said on Monday that the United States would allow small UAVs to fly over people and at night, which means an important step toward widespread commercial use of UAVs for which would be analyzed elaborately in the following parts.

\subsection{Technology Environment}

As for the part of the technical environment, the analysis is divided into two parts, which are Technical resources and infrastructure availability and High-tech labor force talents respectively

\subsubsection{Technical resources and infrastructure availability}

The availability of technology resources and infrastructure provides the conditions for this fundamental innovation of UAV, which will bring a new way for many activities, including military and commercial uses. Although UAVs are not allowed to fly over the United States regularly, there are many possibilities for developing UAVs for other purposes. This technology is in the initial stage of development, but it has shown some potential military functions, such as spying on foreign territory. For example, in the film production industry, six private companies have adopted UAVs in 2014.

\subsubsection{High-tech labor force talents}

In addition, there are still a large number of human capital sources related to technical expertise in the labor market, which provides a feasible opportunity for UAV technology progress. There are also many collaborations between universities and private companies, which conduct research based on UAV development. For example, the "pilotless Pilot School" at the University of delivery and the ITT Institute of technology is a technical school that provides vocational training programs. UAV technology will not just stay at this stage. For example, drones are now used in museums and universities for history or campus tours.

\section{POCD ANALYSIS}

This part analyzes Skydio using the POCD framework, the Deal part will be ignored because of the lack of information.

\subsection{People}

For an anonymous startup with no track record, that level of trust can be alarming. However, Skydio has been recognized across the market, including countries, consumers, and investors in all industries who trust its devices to deliver what the company claims. That can't be realized without the great team.

Skydio co-founder Adam Bry, who was one of the first engineers hired to put Google's Project Wing drone delivery program into practice, studied and helped create autonomous flight systems at MIT, with an emphasis on computer vision. He has extensive experience in drone development and computer vision technologies that can help drones operate safely and autonomously. And Adam Bry is incredibly creative, ambitious, and committed to the dream of bringing humans truly autonomous flying drones. So, after a year and a half working on Google X's drone delivery Project Wing, Bree co-founded Skydio. Investors not only valued Bry's charisma but also trusted his experience, which Bry eventually turned into tens of millions of dollars in investments from various Silicon Valley and technology companies. Bry is not an idealist, but a true industrialist who has lived up to the expectations of investors and consumers, with the debut of the world's first "binocular" unmanned aircraft.

Besides Adam Bry, two co-founders are Abraham Bachrach and Matt Donahoe respectively. Abraham Bachrach also studied the award-winning autonomous flight research program at MIT, starting in 2007. He was also the co-founder and technical lead at Google Project Wing. His experience is rich across computer vision, machine learning, system architecture, and vehicle design. Matt Donahoe is the project co-founder and lead developer of PocketGems' Episode. He has extensive experience with shipping codes used by millions. They all graduate from the Massachusetts Institute of Technology, just like Adam Bry.

It also has trustworthy operating, sales, product, technology, law, HR and finance teams. They are all leading experts in AI, robotics, cameras, and electric vehicles from top companies, research labs, and universities from around the world.

\subsection{Opportunity}

Skydio is the first company in the world to make fully autonomous consumer drones. The company took 
advantage of a gap in the market for consumer drones, which are currently focused on cost and difficulty. For example, Skydio's Skydio R1, a \$2,500 device launched in February that integrates cameras, Sensors and a powerful NVIDIA onboard computer that maps its surroundings, plans and predicts its flight path, and avoids obstacles when tracking individual human objects. Skydio R1 enables the drone to have artificial intelligence capabilities that are less difficult to operate due to its autonomous driving capabilities. This satisfies the customers' needs, likely to enable every home in the United States to have a drone of its own in the future. To ensure that their leading technology will not be imitated beyond others, Skydio invests a lot of money in technology and product improvement. Now their drones are one of the best drones globally and have many major patents in hardware, flight testing, autonomy, and Engineering.

At the same time, Skydio also captured the needs of the enterprise customers in the United States. In the world, DJI's drones can be said to be more than a lot of brands. But Skydio, the nation's first industrial drone, recently launched a new product called the Skydio X2, which aims to capture the enterprising customer base and market share in the U.S. market. On the policy side, Skydio has also seized some policy opportunities and has been working on an industrial drone product that it hopes will compete with DJI's. But an unmanned aerial vehicle (UAV) markets around the world have long based Xinjiang, application field also has long been the top in the industry, technical reserves are very severe, based on the near-monopoly of Xinjiang, Skydio X2 still has their own advantages, there are two reasons: 1, the unicorn Skydio as a native American enterprise, more can obtain the national enterprise customer support. 2. The image transmission distance of the longitude and latitude M300 UAV released by the DJI industry application has reached $15 \mathrm{~km}$. Although Skydio X2 has an image transmission distance of $10 \mathrm{~km}$, which is somewhat less than that of DJI, it has the highest value in the American market.

The biggest disadvantage of Skydio is its endurance. Take R1 for example, its endurance is only about 16 minutes. Although its performance is very strong, due to the relationship between power consumption and volume, it has been mostly used in the field of auto autonomous driving before, and few people have thought about putting it on UAVs. Obstacle avoidance + autonomous flight is cool, but endurance is also a big problem.

\subsection{Context}

\subsubsection{The Novel Coronavirus.}

Skydio is the first airline in the world to use drones against the Novel Coronavirus. Currently, 170 countries/territories worldwide have been affected by the pandemic COVID-19 (novel coronavirus). Viral infections are increasing fivefold every day worldwide, and these data also show the ability to spread across national borders. To date, there is no proven way to treat the disease or stop its spread. Authorities estimate that as many as 5.3 billion people worldwide will be infected in the coming months. How to contain the spread of the virus, drones play an important role. Skydio has deployed autonomous cruise drones to help maintain security during the government's interdiction response to the COVID-19 outbreak. Compared with traditional UAVs, the autonomous cruise UAVs will be easier to operate and save time on operator training.

In response to the sudden outbreak, Skydio's local production in California has been temporarily suspended and orders cannot be shipped at present. The state of California has advised all Bay Area employees to stay home to prevent the spread of COVID-19 as part of the Bay Area's Shelter-In-Place Directive, which runs through early April. But Skydio, which has its own hedge system for emergencies, has not been severely affected by the outbreak, and its inventory can still cope with the current order volume.

\subsubsection{The UAV Industry}

At present, the UAV industry has been widely used in the military, enterprises and families. With the market saturated for both the military and commercial sectors, Skydio's primary goal is to increase its market share and strengthen its position. For individuals, families, consumers, and the trend of the development of the UAV is to reduce costs, improve performance and increase maneuverability. Currently, the consumer's pain points are that UAVs have high prices, poor battery life, and high operation difficulty, so they would not be practical. The next major goal for Skydio is to develop costeffectively, and high-quality products, let every household has its own unmanned aerial vehicles (UAVs), Improve the happiness index, let the drone become our good friend. Now drones can be used in everything from construction site reconnaissance to wedding photography.

\subsubsection{The Government's Attitude}

And the government is also helping the UAV industry develop. In the past, there are a lot of bans on drones. But on December 29, 2020, The U.S. Federal Aviation Administration (FAA) said on Monday that the United States will allow small UAVs to fly over people and at night, which means an important step toward widespread commercial use of UAVs.

FAA said that in most cases, the agency's new regulations for UAVs will require solving safety problems through remote identification technology, which can identify UAVs from the ground. The new rules will be published in the Federal Register in January and 
take effect 60 days after the date of publication. UAV manufacturers will have 18 months to start producing UAVs with remote identification, while operators will have an additional year to provide remote identification. Other, more complex rules will allow drones to operate at night and, in some cases, allow large drones to fly over people[11]. The new regulation cancels the requirement that UAVs must be connected to the Internet to transmit location data and transmit remote identification information through radio frequency broadcasting. UAVs may be banned from use in areas without internet access services if this change is not made. "The new regulations will solve the safety and security problems and pave the way for UAVs to further integrate into our airspace." Steve Dickson, director of the FAA, said, " This brings us one step closer. One day, we will see more UAVs delivering packages and other operations. "

To sum up, through various analyses, it is justified to believe that Skydio is undoubtedly the leader of unicorn enterprises and has great investment value. People should be optimistic about Skydio and believe that this company is worth investing in.

\section{CONCLUSION}

This paper researches the development of UAV companies by analyzing Skydio. Based on PEST and POC models, we analyze the strength and weaknesses of Skydio and precise its opportunity and risk in the future.

Based on the PEST model, we first analyze the political and legal environment and see that the government has recently been discussing the possibility of drafting regulations for commercial drone flights. And this brings an opportunity for drones companies like Skydio. Secondly, we talk about the economic environment. For improving the competitive advantage of enterprises, UAV has become a potential substitute for enterprise logistics activities. In the socio-cultural environment, drones companies face both opportunities and risks. Finally, we analyze the technology environment. The availability of technology resources and infrastructure provides the conditions for this fundamental innovation of UAV.

The POC model is then used to analyze Skydio and find that Skydio has a good management team. It has many opportunities to grow and the context is also good for this company. So Skydio is undoubtedly the leader of unicorn enterprises and has great investment value. We are optimistic about Skydio and believe that this company is worth investing in.

This paper still has limitations. Because of the lack of information, we didn't analyze the deal part of Skydio based on the POCD model. In the future, we would add more variables to the POC model and dip deeper into Skydio and the UAV industry.

\section{REFERENCES}

[1]Carruthers, \& H. (2009). Using pest analysis to improve business performance. Practice, 31(1), 3739.

[2] Gupta, A. . (2013). Environmental and pest analysis: An approach to external business environment.

[3] Ha, H. , \& Coghill, K. . (2006). E-government in singapore - a swot and pest analysis. Asia-Pacific Social Science Review, 6(2).

[4] Halik, J. . (2012). The application of pest analysis based on ebrd and ibrd methodology. Central European Business Review, 1(3), 14-21.

[5] Jae-Woong, B. , \& Geun-Woo, R. . (2010). A global brand of the microsoft company : 4ps and pest analysis. Cultural Industry Research, 10.

[6] Sahlman, W. A. (1990). The structure and governance of venture-capital organizations. Journal of financial economics, 27(2), 473-521.

[7] Barnardo, C., Reyneke, M., Ferreira, C., \& Robertson, J. (2021). GrowBox: the reality of growth challenges for a social entrepreneur in Cape Town. Emerald Emerging Markets Case Studies.

[8] Johnson, A. C., \& Ebben, J. (2017). ArtsApp. comDigitizing the Music School Application Process.

[9] Lukeš, M. Department of Managerial Psychology and Sociology, University of Economics, Czech Republic. Teaching Psychology of Entrepreneurship, 203.

[10] Aure, P. (2014, March). Social entrepreneurship canvas: A visual framework for managing commercial and social value propositions. In DLSU Research Congress.

[11] BEA Data. (2021, March). Personal Income by State, 1st Quarter 2021. Retrieved from https://www.bea.gov/data/income-saving/personalincome-by-state 